\title{
So you want to be a student entrepreneur?
}

\author{
Charles H Jones \& Andrew Hill \\ Practical tips for graduate students with an aspiration to start a life science venture.
}

W hile finishing our $\mathrm{PhD}$ studies, we decided to found a company, Abcombi Biosciences, with the intent of commercializing a vaccine we had developed for combatting pneumococcal disease. Because our technology was developed in a university laboratory, three of the four founding members of our startup team were academics-only one of us possessed direct industrial experience. Although this established our academic credentials, we quickly discovered that our lack of broad business acumen meant that our initial commercialization plans were ill-conceived and failed to take into account many of the challenges in commercializing a discovery-stage technology. After realizing that our core team was not equipped for the challenge ahead, we started over.

This article is our attempt to help other aspiring scientist-entrepreneurs from making the same mistakes. It provides reflections and advice (Table 1) from our ongoing journey as graduate students turned entrepreneurs. As with many other aspiring small businesses, we learned the hard way, through trial and error. We provide below the framework and strategies most appropriate to students interested in navigating the intricate interplay of technological and commercial development in biotech, which often act at different scales-from intellectual novelty to economic feasibility. As this information would have been highly beneficial to us at Abcombi's founding, we hope this article will prove useful to others seeking to start their life science ventures.

\section{Building credibility}

A student entrepreneur's biggest hurdle is credibility. It permeates every aspect of business development and is an extension of your

Charles Jones and Andrew Hill are at Abcombi Biosciences Inc., Buffalo, New York, USA. e-mail: charles.jones@abcombibio.com or andrew.hill@abcombibio.com ability to deliver results in a timely and professional manner. During the early stages of a company, the founders' credibility is critical for selling the company's potential for success. Furthermore, building your company's credibility must be your highest priority-it improves your ability to raise capital, attract partners, and recruit competitively. During this process, it is important that you routinely perform honest assessments of your company's strengths and limitations. These assessments will tell you where to first focus your efforts. This will not only improve your company's product(s), but also address concerns raised by potential investors.

Scientific credibility. First, you'll need to look at your scientific underpinnings. As an old adage goes, "trust takes years to build, but seconds to lose." For students, your scientific credibility is directly linked to success in research, curriculum, and practical experience, such as internships. When founding a company, you will, in particular, face concerns from investors and potential collaborators if you have not completed your targeted terminal degrees. But this can be overcome by establishing a strong track record as a scientist through publishing research and review articles, and securing patents. This collectively demonstrates your versatility in the respective field.

Intellectual property. Building a strong intellectual property (IP) portfolio for your company is another way to build credibility. For student entrepreneurs this again can be a challenge, as students rarely possess ownership of the IP generated from their research laboratory and must negotiate licensing rights from their respective university. This is a substantial challenge because, in our experience, the university has little incentive to structure a licensing deal with beneficial terms for the student. In our own licensing negotiations, we greatly benefited from practicing negotiation tactics learned through books and courses.
This showed us how to initiate discussions with set target and walkaway terms, and improved our negotiating skills, and should be useful in partnering discussions for your company.

In addition to building your IP, you will need to identify potential competing technologies through patent searches and establish your 'freedom to operate'-a legal term meaning that your IP does not infringe on any existing patents. This is time-intensive and expensive, but it's critical for identifying how others might circumvent your company's IP. We recommend seeking funds from angel investors to support such activities and hiring a professional firm to analyze your patent landscape for potential acquisition targets. Typically, potential investors will assess the protection of your company's IP during technical due diligence, and expanding your IP portfolio beyond your initial patents will strengthen the protection of your technology.

Business credibility. There's an unfortunate assumption among researchers that a stellar IP portfolio and a promising pipeline will sell your company by itself. It won't. Your company's business credibility is primarily derived from the collective experience and ability of your team to navigate the diverse issues your company will inevitably face. We realized this after several of our initial attempts to raise funding failed.

One means to build credibility in business is through networking at relevant conferences. Although as researchers, we attended conferences with long and established records, such as those sponsored by the American Society of Microbiology and American Chemical Society, that offer limited exposure to industry. We discovered that our business network could be built more efficiently by attending industrially linked conferences, such as the Biotechnology Innovation Organization (BIO) International Convention and the World Vaccine Congress (WVC). This enabled us to not only establish critical industrial contacts but also learn 


\author{
Table 1 Checklist of actionable items for aspiring student entrepreneurs

Attribute Recommendations \\ Establish your scien- • Build your reputation within your company's field by soliciting opportunities to \\ tific credibility with write review articles \\ industry - Attend specialized industry-oriented conferences and actively network \\ Build your IP port- $\quad$ - Learn and apply various negotiation techniques to secure licensing rights to the \\ folio IP your company requires to operate \\ - Evaluate the patent landscape surrounding your company's product(s) to iden- \\ tify potential targets for acquisition \\ Gain recognition as a - Build connections within the business world to identify mentors who can guide \\ business leader you and provide validation of your company \\ - Build your network by engaging the connections of your mentor(s) and taking \\ advantage of the opportunity to learn from their collective experience \\ Understand what is - Identify the market for your product: is it sufficiently large to appeal to investors? \\ required to develop a - Determine the key advantages of your product: \\ competitive product Lower cost \\ Superior coverage, efficacy \\ Market disruption
}

Build a product that - Determine what is important for a product within the market you are seeking to is realistic to develop enter:

and commercialize

o Determine the key features to optimize cost and efficacy (80-20 rule)

o Limit your product design to contain features that are currently accepted in clinical applications

o If your product is highly novel, take steps to reduce its complexity and therefore perceived risk

- Identify what you can use as a measure of efficacy and whether your regulatory pathway is reasonable

Achieve flight (get- $\quad$ Become active in business plan competitions, starting initially in student comting off the ground) petitions

- Identify various forms of small-scale funding that can enable you to de-risk your company

Angel investors

STTR and SBIR grants

- Enter discussions with organizations that provide dilutive funding with realistic expectations; innovation is secondary to the likelihood of commercial viability

- Expect thorough due-diligence as you progress through negotiations

Balance graduate student and entrepreneur lifestyle

- Expect to work 80-100 hours per week and make efforts to organize your time efficiently

- Maintain an open dialog with your advisor about your company and discuss strategies to ensure that the interests both of you are protected typically lead to the pursuit of highly novel solutions that pertain to issues of interest to either the student or advisor-do not necessarily translate into solutions considered commercially relevant by investors or major corporations. Idealistic academic solutions often ignore numerous business-related constraints and therefore may not represent a viable commercial opportunity.

Thus, aspiring entrepreneurs should focus on developing 'working solutions' that are cost-effective, capable of overcoming regulatory hurdles, can be delivered practically to the target demographic, and possess a competitive advantage in a respectable market with a reasonable promise of sufficient remuneration. Bridging this gap means students need to overcome their academic biases to identify commercially viable products.

Even if your company has brought an asset to the brink of human testing, safety trials, proof of efficacy, and multi-center human testing (phases 1 through 3 ) can cost an average of \$22.2-71.3 million in the United States, depending on the indication ${ }^{1}$. Thus, a critical issue is whether your lead product addresses an area of pressing need and can do so with the shortest and most streamlined development pathway. Furthermore, even if you have identified a commercially attractive market, you also need to demonstrate that your product has clear advantages over existing products (e.g., standard-of-care products) from competitors. Those advantages might include a substantial reduction in manufacturing costs, a superior product, or the ability to address a market issue not being currently addressed. Whatever the case, you must do a thorough product comparison to current commercial vaccines and therapeutics, as well as to those currently in development.

One of the first considerations is cost. Although you may not be able to find out how much your competitors spend to produce their products (called the cost of goods (COGs)), you can get a ballpark comparison using current market prices while assuming a significant markup. For example, if a competitor's product is offered using a tiered-pricing structure (i.e., different markets/countries can purchase at discounted rates), you can approximate their COGS based upon third-world countries' prices as these markets are often not capable of purchasing at a premium. However, if you plan to enter an established market as an entrepreneur, you should always endeavor to develop a product that solves a pressing need, rather than one that is simply cheaper. Creating an improved 'me too' product may be appealing in large markets, but startups lack the resources to compete with large multinationals that possess 
an economy of scale advantage (i.e., the ability to produce goods at a lower cost due to the size of their production process). For example, in the vaccine sector where Abcombi operates, the five largest players control $75 \%$ of the global market, according to an analysis by the Program for Appropriate Technology in Health (Seattle), and are capable of competing at price points well below levels required for sustainability for a startup.

To determine whether or not your indication has superior performance, develop a comprehensive understanding of the market you are seeking to enter and the problems within it. For example, if you are developing an antibacterial asset, first determine what the rate of resistance development is for other antibacterial drugs against your target pathogen, followed by quantifying your product's superiority over competitors, and finally, determine the limitations of competing interventions towards the goal of designing solutions. Understanding the market you plan to enter better positions you to develop a product that clearly solves a pressing need.

\section{Commercial feasibility}

A common academic bias is that the best solutions are both novel and provide the strongest impact, but as an entrepreneur, you should focus on a 'good enough' product, one that possesses $80 \%$ of the functionality at $20 \%$ of the cost. This is called the $80-20$ rule, and is derived from factors that aren't always accounted for in academic research.

Businesses are profit-driven, so your primary objective should be shepherding a promising product to market rather than spending an extended period on its perfection. This is especially important if you are considering the addition of novel features to obtain the strongest possible clinical outcome. The healthcare industry's take on innovation has been shaped by years of failures and delays, and it has thus shifted its emphasis to innovations that add the most value to the patient, manufacturing process (e.g., cost reductions), distribution channels, or product use. Consequently, completing clinical trials using novel technologies is often arduous and you may not possess a clear regulatory pathway. For example, use of novel adjuvants in vaccines is not permitted in infants and generally requires demonstration that the adjuvant is both safe and necessary for efficacy. By designing your product with your endgame in mind, you can substantially reduce the complexity of its path forward.

As you design your product and plan your regulatory pathway, be prepared to make adjustments. Unless you have a clear and realistic pathway to licensure (i.e., navigating your product's respective regulations), all your previous $\mathrm{R} \& \mathrm{D}$ efforts will have been made in vain (Box 1).

You should create a clinical development plan and map out your regulatory pathway before finalizing your indications. We drafted our plan and regulatory pathway internally, but refined them through contracting consultants that possessed substantial experience in major pharmaceutical companies familiar with vaccine development. When completing these plans we modified our vaccine composition and marketing strategy after gaining an appreciation for how difficult it is to earn regulatory approval.

The take-home message is that if you develop a realistic path to licensure early in your endeavors, you will save a lot of time and effort later. Furthermore, you also will be better prepared for discussions with investors and present a more attractive investment opportunity. Our experience taught us that having plans for marketing and obtaining licensure is critical to obtaining funding for even preclinical research.

\section{Achieving flight}

After identifying your product and founding your company, you'll need funding. There are two kinds of investments: dilutive and non-dilutive of company equity. You'll want to understand the positives and negatives associated with each type of funding, which will improve your likelihood of matching the interests of particular sources. In preparation of potential funding events, you will need to take steps to improve your company's investor attractiveness. These steps include identifying key actionable items that build your company's value, developing a clear (and realistic) vision for your company, and integrating any feedback you receive.

Funding. How can a student raise sufficient capital? The lack of credibility here complicates things, especially with traditional routes such as venture capital. This means that beyond raising funds from the three F's (friends, family, and fools), you will need to consider a range of investors and investment vehicles that are a realistic avenue for students, as well as the pros and cons of each route ${ }^{2}$. Specifically, student competitions, such as those around business plans, represent an ideal starting point because their mechanisms are designed to teach and refine the skills needed for securing funding from traditional routes. These opportunities are often offered through your university's business school.

Once you've gained experience in student competitions, you should transition to larger business-related funding competitions, ranging from local economic initiatives, such as the 43 North business competition in Buffalo, New York, to national and international entities $^{3}$. There are also government programs that can help ${ }^{4}$. Specifically, if you are a graduate student based in the United States, you can apply for non-dilutive Small Business Innovation Research (SBIR) or Small Business Technology Transfer (STTR) grants offered by the US National Institutes of Health (NIH) or the National Science Foundation.

These government business grants are similar to traditional academic funding sources, such as NIH R01, R21, and R03 grants, but

\section{Box 1 A cautionary tale}

It is important to understand all the challenges along the discovery, preclinical and clinical development pathway. We learned this lesson while developing our inexpensive, potentially universal (as a standalone) common protein vaccine for pneumococcal disease. Ultimately, our entire solution turned out to be non-viable because we had failed to take into account a key clinical development consideration.

Because the composition of our vaccine candidate differed substantially from the composition of current commercial vaccines, we did not possess an established correlate of protection to evaluate our vaccine's efficacy. This was further complicated by regulations that prevent the standard of care (in this case, Prevnar; pneumococcal polysaccharide conjugate vaccine) from being denied to patients. Consequently, our phase 3 trial needed to demonstrate that co-vaccination of our indication with Prevnar significantly reduced the incidence of pneumococcal disease caused by serotypes Prevnar does not provide protection against. Because the incidence of invasive pneumococcal disease in regions that employ routine vaccination with Prevnar is below 100 per 100,000, a power analysis demonstrating our vaccine's efficacy necessitated a massive phase 3 trial with tens of thousands of patients. Consequently, the costs associated with obtaining regulatory approval for our vaccine drastically outweighed its potential benefits. As a consequence, we were forced to redesign our vaccine from the ground up. Lesson learnt. 


\begin{tabular}{|c|c|c|}
\hline Funding stage & $\begin{array}{l}\text { Typical funding } \\
\text { range ( } \$ \text { millions) }\end{array}$ & Purpose of funding \\
\hline \multirow[t]{2}{*}{ Seed } & $0.5-3$ & - Business plan development \\
\hline & & - Establish IP portfolio for proposed indications \\
\hline \multirow[t]{3}{*}{ Series A } & $5-20$ & - Discovery-stage experiments \\
\hline & & - Preclinical animal studies \\
\hline & & - Process development, manufacturing, controls \\
\hline Series B & $25-50$ & - Early clinical studies (generally pre-phase 2) \\
\hline \multirow[t]{3}{*}{ Series $\mathrm{C}$, and following } & $50-100$ & - Pivotal studies (phase 2 and 3 ) \\
\hline & & - Regulatory licensure \\
\hline & & - Commercialization \\
\hline
\end{tabular}

the objective here is to provide funding to support proof-of-concept studies or to further the product maturation necessary for a company to reach development milestones that can trigger further investment rounds. These non-dilutive funds are limited and will not be enough to sustain commercial development, but they are perfect vehicles for building credibility, and they should help create opportunities for more traditional funding routes in the venture capital community.

Venture capitalist expectations. Bear in mind when seeking dilutive funding from investors and organizations that they are focused on the best chance at a positive return. It is important to align with investors whose exit strategies marry with your plans for company development. As you proceed through negotiations, expect intense due diligence, in which your team, technology, and corporate strategy will be thoroughly evaluated to determine your company's value and likelihood for success. If these organizations decide to provide funding for your company, they will typically obtain one or more seats on your board of directors. If a substantial amount of capital is to be provided through dilutive funding, it is likely your team will be replaced in one or more senior leadership positions by an individual with more experience. Although this is a scenario you will not likely encounter with non-dilutive funding, and while being removed from a management role may not be your desired outcome, you should view receiving dilutive funding as a milestone of company success. It will provide access to advice, information, market expertise, and it will expand your network.

Awarded venture capital is typically divided into several rounds, given to help achieve specific goals. The funding stages, typical amounts, and purposes are shown in Table 2. As you grow your company, be realistic about the amounts you ask for and what milestones you can achieve.

Although innovative science can be one aspect for attracting investment, venture capitalist or family offices are often more focused on the capabilities of your team, your clinical development plan and regulatory pathway, and commercialization strategy. Typically, they will accept your science at face value upon first meeting, and determine the shortcomings of your product during the technical due diligence phase.

Also, keep in mind that venture capitalists generally (though there are exceptions) are not interested in helping you grow as an individual or benefiting society at large. Their aim is to find projects that have the best chance of maximizing the return on investment of the limited partners in the fund in a limited time horizon (typically less than 10 years). In a recent assessment of the development of clinical success rates for 2006-2015 released by the Biotechnology Innovation Organization (BIO; Washington, DC), the likelihood of licensure from phase 1 therapies across all indications was $\sim 10 \%$. The greatest risk reduction occurs after phase 2, when the likelihood of licensure increases to $50 \%$. All the more reason to have a strategy for demonstrating efficacy and developing your regulatory strategy before seeking investment.

\section{A balanced life}

If you are starting a company as a graduate student, you will face constant demand and substantial strain on your time. It would be difficult to make meaningful progress in your startup unless you commit at least 40 hours a week toward building value. You'll also likely need to commit at least 40 hours weekly to graduate research and studies. This is the minimum workload, and we found it was regularly surpassed during 'crunch' periods. Often, we needed to invest more than 100 hours per week, or greater than 14 hours a day, to prepare funding applications, corporate presentations, publications, or other major documents.

This is demanding, and it will likely impact your graduate research. Make sure you discuss your company and its development plans with your $\mathrm{PhD}$ advisor, so you can protect both your academic and entrepreneurial interests. Open dialog helps avoid lapses in communication, whereas poor communication leads to all sorts of negative interactions. In situations where you find company priorities conflicting with your advisor's demands, focus on empathizing with their specific concerns and discussing actions you can take to alleviate them. This is another instance in which negotiation skills are highly valuable.

These demands can be intimidating. To mitigate this, we maintained a detailed schedule to ensure that we made progress on each item daily. By keeping on schedule, we avoided rushing items as they got close to their due date. Time management in this manner is absolutely critical; your ability to execute tasks in a timely manner reflects on your credibility and your company's credibility.

\section{Conclusions}

Putting aside the myriad challenges associated with launching a life science venture, we contend that students are in a unique position to excel. One of your greatest strengths is that you are isolated from the burden of your industry's conventional wisdom. You can harness this advantage using your academic creativity to solve critical problems by developing solutions that are neglected by the low-risk scope of large companies. At no time in your life will you be likely to have more freedom and less personal commitments to be able to pursue your startup dreams.

Creativity, however, needs to be tempered by the necessities of the marketplace. Building a company requires a desire to learn from others, passion for developing an impactful product, and willingness to make sacrifices. You will constantly learn as you go, and at each step you should refine your company's vision and products, raising your credibility and better positioning yourself to attract investors.

\section{COMPETING FINANCIAL INTERESTS}

The authors declare no competing financial interests.

1. Sertkaya, A., Wong, H.H., Jessup, A. \& Beleche, T. Clin Trials 13, 117-126 (2016).

2. Ford, D. \& Nelsen, B. Nat. Biotechnol. 32, 15-23 (2014).

3. Sekula, R., Bakhru, S. \& Zappe, S. Nat. Biotechnol. 27, 793-796 (2009).

4. Beylin, D., Chrisman, C.J. \& Weingarten, M. Nat. Biotechnol. 29, 567-570 (2011) 